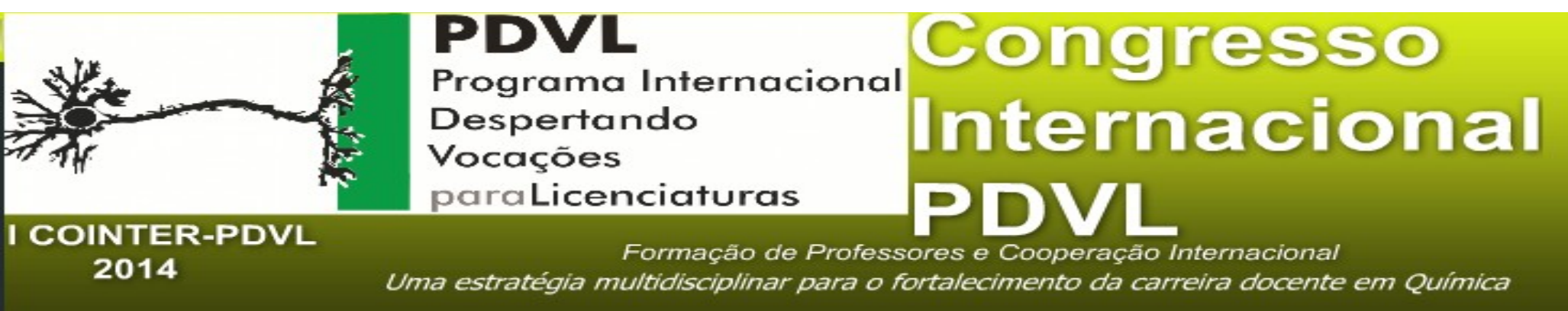

\title{
CÁLCULO ESTEQUIOMÉTRICO: UMA ABORDAGEM INTRODUTÓRIAA PARTIR DA EXPERIMENTAÇÃO
}

\author{
ANJOS ${ }^{1}$, Carlos. Augusto dos; ANJOS ${ }^{2}$. Luiz Carlos Araújo; CRUZ ${ }^{3}$, José Brito \\ da; SILVA ${ }^{4}$, Aluízio Galdino da.
}

${ }^{1}$ Graduando em Licenciatura em Química do IFPE - Campus Ipojuca, e-mail: carlosananda62@gmail.com.

${ }^{2}$ Doutor em Química pela UFPE e professor de Química do IFPE - Campus Ipojuca, e-mail: luiscarlos@ipojuca.ifpe.edu.br.

${ }^{3}$ Doutorando em Química pela UFPE e professor de Química do IFPE - Campus Ipojuca, e-mail: josebrito@ipojuca.ifpe.edu.br.

${ }^{4}$ Doutorando em Química pela UFPE e professor de Química do IFPE - Campus Ipojuca, e-mail: aluiziogaldino@ipojuca.ifpe.edu.br.

INTRODUÇÃO

A qualidade do Ensino de Ciências e a prática docente tem se colocado como alvo constante de pesquisas. A Química faz parte do cotidiano de todos, segundo Bizzo (2012, p. 16) relata: “o domínio dos fundamentos científicos hoje em dia é indispensável para que se possam realizar tarefas tão triviais como ler um jornal ou assistir à televisão [...]”. O conteúdo de Cálculo Estequiométrico no ensino médio é considerado difícil e complexo por necessitar de conceitos prévios de matemática, os quais nem sempre são dominados pelos estudantes. A contextualização e o uso de experimentos nas aulas de Química podem constituir uma importante ferramenta para auxiliar os estudantes na compreensão dos conceitos estequiométricos.

De acordo com Maldaner (2003, p. 144) e em concordância com as Diretrizes Curriculares Nacionais para o Ensino Médio (BRASIL, 2011): “o Ensino de Química deve ser voltado para construção e reconstrução dos conceitos científicos nas atividades 
de sala de aula”. Surge, portanto, a necessidade da experimentação como um instrumento para tornar as aulas de Química mais estimulante. Assim sendo, a intervenção aplicada objetivou verificar o nível de aprendizado dos estudantes após a aula apresentada quanto ao componente Cálculo Estequiométrico nos seus aspectos teóricos (conceito de proporções constantes e conservação da matéria) e práticos. Outro ponto relevante foi identificar as dificuldades surgidas durante o processo de ensinoaprendizagem a fim de servir como indicador de melhoria para futuras intervenções.

\section{FUNDAMENTAÇÃO TEÓRICA}

Compreende-se que a Química enquanto ciência compreende o estudo da composição dos materiais bem como as transformações que eles podem vir a sofrer. “Os materiais são constituídos de matéria, e as transformações da matéria, ou reações químicas, envolvem o consumo ou a liberação de energia” (BRADY; HUMISTON, 1994).

No entanto, seu ensino continua em muitos casos reduzidos a transmissão de informações fixas e isoladas por parte do professor e exigência de memorização dos conteúdos apresentados pelos estudantes, produzindo baixos níveis de aprendizagem cognitiva e com temáticas descontextualidas com o cotidiano desses estudantes. Sabese, porém, que o grau de dificuldade de certos conteúdos de química necessita de saberes pertencente a outras áreas. No cálculo estequiométrico, fazem-se necessários conhecimentos prévios referentes à nomenclatura de grupos funcionais, regras de solubilidade, balanceamento de reações, proporções molares, solubilidade, etc., além, dos saberes matemático.

A palavra estequiometria vem do grego (stoicheon = elemento e metron = medida) este termo foi introduzido em 1792 por Richter e faz referência a medida dos elementos químicos nas substâncias. Atualmente, a Estequiometria compreende as informações quantitativas relacionadas a fórmulas e equações químicas, e está baseada nas leis ponderais, principalmente, na lei da conservação das massas e na lei das proporções fixas (ou definidas).

Para Lavoisier (1875 apud CAZZARO, 1999) o enunciado da lei da conservação de massa de sua autoria descreve que “[...] a soma das massas dos reagentes é sempre 
igual à soma das massas dos produtos”. Por sua vez, Proust (1799 apud CAZZARO, 1999) enuncia na lei das proporções fixas que “[...] uma substância qualquer que seja sua origem, apresenta sempre a mesma composição em massa”. Essas duas leis, conhecidas como "Leis ponderais”, contribuíram para o estabelecimento da Química como ciência e, são subjacentes à teoria atômica de Dalton (CAZZARO, 1999).

De acordo com os Parâmetros Curriculares Nacionais para o aprendizado de Química no ensino médio, descreve que o aprendizado de Química no ensino médio “[...] deve possibilitar ao estudante a compreensão tanto dos processos químicos em si, quanto da construção de um conhecimento científico em estreita relação com as aplicações tecnológicas e suas implicações ambientais, sociais, políticas e econômicas” (PCNEM, 2002)

Assim sendo, faz-se necessário que a prática docente se construa dentro de uma abordagem contextualizada, trazendo os conteúdos de Química para a realidade do estudante e de seu cotidiano a fim de que ocorra uma aprendizagem significativa dos temas trabalhados em sala de aula, formando nestes estudantes uma cidadania consciente e integrada com o mundo a sua volta.

\section{METODOLOGIA}

Este trabalho foi desenvolvido em parceria com a Escola Técnica Estadual Epitácio Pessoa, situada no município de Cabo de Santo Agostinho - PE. A intervenção foi realizada com 40 estudantes da $2^{\text {a }}$ série do ensino médio (turma D) em dois momentos distintos.

O primeiro ocorreu com uma abordagem contextualizada de Cálculo Estequiométrico a partir de exemplos do cotidiano, como fazer um bolo (proporção dos ingredientes) e a combustão da gasolina nos automóveis. Uma das formas de verificação do aprendizado foi por meio da interatividade dos estudantes ao responderem perguntas sobre o tema estudado. No segundo momento, foi realizado um experimento em que a massa do bicarbonato de sódio $\left(\mathrm{NaHCO}_{3}\right)$ foi determinada em um comprimido efervescente a partir da massa de dióxido de carbono (CO2) produzido na reação (CAZZARO, 1999). 
Para coleta de dados deste segundo momento utilizou-se como instrumento de pesquisa um questionário contendo 3 perguntas: 1) Você gostou da forma como o tema estequiometria foi apresentado? Justifique. 2) Qual é a parte da Estequiometria que você menos gosta? 3) Você já participou de aulas interativas de Química antes?

\section{RESULTADO E DISCUSSÕES}

O experimento (Fig. 1) realizado pode contribuir para a fixação dos conceitos de forma estimulante. Ressalta-se ainda que uma abordagem prática e contextualizada é fundamental no ensino de ciências. Isto fica claro na seguinte fala: “estudar desse jeito é mais gostoso e fácil de entender”. Em medicina, o bicarbonato de sódio $\left(\mathrm{NaHCO}_{3}\right)$ é utilizado como antiácido estomacal neutralizando o excesso de $\mathrm{HCl}$ do suco gástrico. Cada comprimido contém 1,854 mg (aproximadamente 1,8 g) de NaHCO 3, 400 mg de $\mathrm{Na}_{2} \mathrm{CO}$ 3, $325 \mathrm{mg}$ de ácido acetilsalicílico e 1,413 mg de ácido cítrico. O resultado encontrado (Fig. 2) pode ser considerado satisfatório.

De acordo com os resultados do questionário aplicado, 85\% dos estudantes gostaram do método utilizado para ensinar o Cálculo Estequiométrico como mostrado no seguinte posicionamento: “usaram experiências e nos mostraram que a Química está presente nosso dia-a-dia”. O experimento torna a aula mais interativa, levando a participação de todos os envolvidos no processo de ensino- aprendizagem. Para a segunda pergunta, 91\% dos estudantes declararam ter dificuldades quanto à matemática. Uma das respostas foi: “adorei o assunto, mas não gostei do cálculo, alguns são muito difíceis”. 
REAÇÃO DO SONRISAL (Equação)

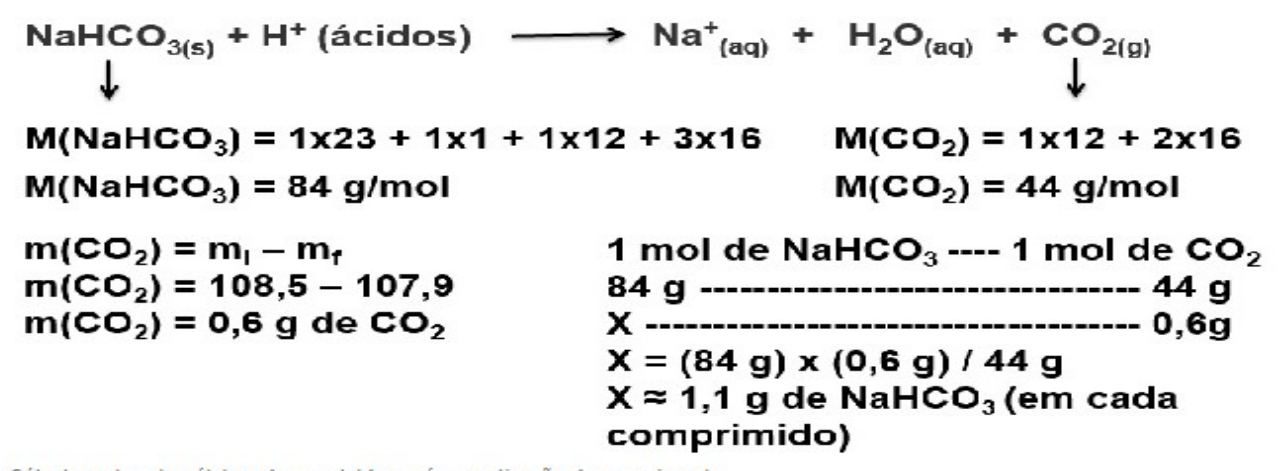

Daí percebe-se a importância da contextualização e da interdisciplinaridade, já que facilita a integração entre os conhecimentos prévios dos estudantes e os novos conceitos. Na terceira pergunta $78 \%$ dos estudantes responderam negativamente e assinalaram o desejo de assistir mais aulas neste formato: “deveríamos ter mais aulas assim dinâmicas e divertidas. Fizeram a gente aprender brincando”. Trazer o conhecimento para o nível de entendimento do estudante promove o interesse de buscar por novos desafios.

\section{CONCLUSÕES}

Foi possível perceber por meio do questionário aplicado, a importância de propor metodologias diferenciadas, de forma contextualizada, apoiadas na experimentação. Isto estimulou nos estudantes um interesse maior em estudar mais sobre Cálculo Estequiométrico, além de diminuir a distância do ensino teórico para o cotidiano do estudante.

\section{REFERÊNCIA}

\section{Figura 1}

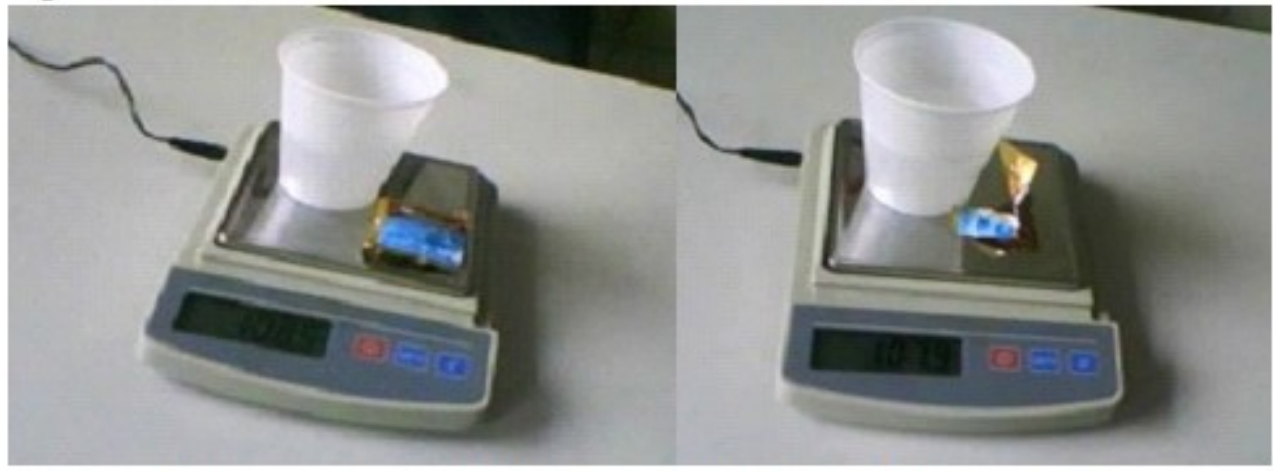

Pesagem do béquer, água e comprimido antes (esquerda) e depois (direita) da reação. 
BRADY, James E.; HUMISTON, Gerard E. Química Geral. 2. ed. Rio de Janeiro: Livros Técnicos e Científicos Editora, 1986, (reimpressão 1994).

BRASIL. [Lei Darcy ribeiro (1996)]. LDB: Lei de Diretrizes e Bases da Educação Nacional: lei $n^{0}$ 9.394, de 20 de dezembro de 1996, que estabelece as diretrizes e bases da educação nacional. - 6. ed. - Brasília: Câmara dos Deputados, Edições Câmara, 2011.

Ministério da Educação, Secretaria de Educação Média e Tecnológica. PCN+ Ensino Médio: Orientações educacionais complementares aos Parâmetros Curriculares Nacionais. Brasília: 2002.

BIZZO, N. Ciências: fácil ou difícil? 2ª edição, Editora Biruta São Paulo - 2012.

CAZZARO, F. Um Experimento Envolvendo Estequiometria, Química Nova na Escola. Vol. 10, p. 53-54, Nov. 1999.

MALDANER, O. A. A Formação Inicial e Continuada de Professores de Química: professor/pesquisador. $2^{\text {a }}$ Ed. Editora Unijuí, São Paulo - 2003.

SANTOS, W. L. P., MÓL, G. S. (coord.) - Química e Sociedade. Editora Nova Geração, São Paulo, 2005 - "PEQUIS - Projeto de Ensino de Química e Sociedade”. 